\title{
Project Pre-mortem using Prospective Hindsight: An Unexplored Tool to address Healthcare Projects Implementation barriers.
}

\section{Abhishek Joshi ${ }^{1}$, Ashok M Mehendale ${ }^{2}$}

${ }^{1}$ Associate Professor, Department of Community Medicine, Datta Meghe Institute of Medical Sciences (Deemed to be University), Sawangi (M), Wardha; ${ }^{2}$ Professor \& Head, Department of Community Medicine, Datta Meghe Institute of Medical Sciences (Deemed to be University), Sawangi (M), Wardha, Maharashtra.

\section{Corresponding Author}

Dr.Abhishek Joshi, Associate Professor, Department of Community Medicine, Datta Meghe Institute of Medical Sciences (Deemed to be University), Sawangi (M), Wardha, Maharashtra- 442004

E Mail ID: abhishekunjoshi@yahoo.com

\section{Citation}

Joshi A, Mehendale AM. Project Premortem using Prospective Hindsight: An Unexplored Tool to address Healthcare Projects Implementation barriers. Indian J Comm Health. 2021;33(2):415-416. https://doi.org/10.47203/IJCH.2021.v33i02.039

Source of Funding: Nil Conflict of Interest: None declared

\section{Article Cycle}

Received: 12/05/2021; Revision: 11/06/2021; Accepted:22/06/2021; Published:30/06/2021

This work is licensed under a Creative Commons Attribution 4.0 International License.

Sir,

Many Healthcare initiatives \& Projects are planned in Healthcare sector and usually after the initial sensitization sessions and Brainstorming among stakeholders the Projects are implemented. Monitoring and Review/Evaluation is done at the end of Project duration or during some specifically decided time interval as per standard practices.

Strength, weakness, opportunities \& threat (SWOT) analysis or critical evaluation/analysis is done. If the Project Objectives are not achieved as expected the insights gained by these methods are used as lessons learnt which are to be kept in Mind while planning for next cycle of the project or while planning some new Project if relevant to it. This end of project evaluation is in fact postmortem of the project.

Project Pre Mortem as a Managerial tool has been a known concept for Business related Projects.

Mitchell et al(1) in 1989 coined a term prospective hindsight that assumes imagining an event has already occurred increases the ability to identify reasons for future outcomes by $30 \%$.

One phenomenon observed as a potential contributor of Project failure by Janis et al(2) is 'groupthink', where a psychological pressure for consensus causes those who disagree to suppress concerns during Project initiation phase, and where the group is less likely to consider alternative decisions.
Gary Klein (3) used this concept of prospective hindsight to devise a method called a pre-mortem, which helps project teams identify risks at the outset and state that a pre-mortem is the hypothetical opposite of a postmortem.

A pre-mortem in a business setting comes at the beginning of a project rather than the end, so that the project can be improved during the initiation stage rather than autopsied afterwards.

It differs from a typical critical appraisal or Brainstorming in which project team members are asked what might go wrong, the pre-mortem operates on the assumption that the "patient" (read project) has died (read failed), and so asks what did go wrong. The team members' task is to generate probable reasons for the project's failure (3).

This Method been used sparsely as a tool for Efficient and effective project management in Health care delivery related Projects/schemes/initiatives even though this method has been evaluated by Heather Gilmartin et al(4) in a Hospital setting.

We at our institute employed this method and compared and contrasted it with the method more frequently used at our Institute the Brainstorming method.

Our Institute has a tertiary care medical college teaching hospital through which we had decided to launch a project for population from rural communities from around 30 kilometers distance from the hospital with a view to increase the access of beneficiaries to subsidized health 
schemes from both government sector and In house schemes run by our Hospital.

Core committee for healthcare initiatives team of the hospital framed the basic framework of the Project and the sensitization meeting was followed up by Brainstorming session followed by kick off meeting and project implementation.

Within a fortnight of launch of the project the expected results as per projections from brainstorming session were far from achieved and same was confirmed during first monthly review meeting.

During the first monthly review meeting the Core team decided to apply the planning tool of Project Pre mortem using prospective hindsight as an alternative tool to Brainstorming and also as a measure to salvage the Project while still in early implementation stage.

All the Preparation was made by thorough discussion with core team regarding method of conducting the session for project pre-mortem, who all shall be participants for session, pros \& cons of the tool. Along with all the in house stakeholders the Project Pre-mortem team also included five randomly selected beneficiaries from the villages where this project was expected to be implemented.

All the members were assembled in conference room and explained about the session. They were then told that that the project has failed to fulfill its Objectives and were asked to reflect on to it and write down plausible causes for the same pertaining to their area of work or in general based on their prior experience in executing the community based health care projects in the past.

Once they wrote down their assumptions the sheets were passed between the participants and if any anyone volunteered to add to the issues identified by their peers they could add to it.

The inputs were read out by the Project Co-ordinator one by one and the final list of probable reasons was finalized with consensus amongst the group. We then collected the final mutually agreed responses and were able to generate at least five plausible implementation barriers or reasons that were not contemplated or shared during the brainstorming sessions we had conducted earlier with the same team members.

It was decided to correct the implementation barriers which were identified by the method and had no extra cost bearing on the budget allocated to the project while the corrective measures requiring extra budgetary provisions were put up before the Authorities.

It also gave us insight regarding dilemma of the team members to point out the loopholes at the outset because of fear or worry of being called out for being dissenter or mistaken for being impolite at the outset during the usual Brainstorming sessions \& sensitization meetings.

The projected targets were better achieved as observed in the next monthly review meeting as compared to before even with only three of the corrective measures actually implemented amongst the five that were proposed. Addressing the weaknesses and threats can improve the structural integrity and action of a project in motion, thereby improving the strengths and maybe identifying new opportunities along the way (5).

We opine that using Prospective Hindsight as a Project pre mortem tool is cost effective and Feasible tool as compared to end of Project autopsy and can pre-empt the project failure and address the implementation barriers for health care projects.

We conclude that this method should be utilized more frequently as a planning tool if not a sole method but at least as a complementary method along with the existing Planning Tools for various Healthcare Projects so as to provide greater insight into risks and identify issues that may not have been considered before and thereby increase the likely hood of project success and to benefit its stakeholders as intended rather than allowing the Project to fail and doing a project autopsy at the end which might help everyone except the Project \& the beneficiary for whom the project was intended at first place.

\section{References}

1. Mitchell DJ, Edward Russo J, Pennington N. Back to the future: Temporal perspective in the explanation of events. Journal of Behavioral Decision Making. 1989;2(1):25-38. Available at https://onlinelibrary.wiley.com/doi/abs/10.1002/bdm.396002010 $\underline{3}$

2. Janis IL. Victims of Groupthink: A psychological study of foreignpolicy decisions and fiascos. Avilable at https://www.semanticscholar.org/paper/Irving-L.-Janis\%27victims-of-groupthink-

Hart/7dfe15a79c2762975d4f3e260e6d472f724328b8. (Accessed on 30.06.2021).

3. Klein G. Performing a project premortem. Harvard business review. 2007;85(9):18-9.

4. Gilmartin $H$, Lawrence $E$, Leonard $C$, McCreight $M$, Kelley L, Lippmann B, Coy A, Burke RE. Brainwriting Premortem: A Novel Focus Group Method to Engage Stakeholders and Identify Preimplementation Barriers. J Nurs Care Qual. 2019;34(2):94-100. doi: 10.1097/NCQ.0000000000000360. PMID: 30148746; PMCID: PMC6493673.

5. Mills JK, McKimm J. Pre-empting project failure by using a premortem. Br J Hosp Med (Lond). 2017;78(10):584-585. doi: 10.12968/hmed.2017.78.10.584. PMID: 29019725. 